Review

\title{
Leaf Length Variation in Perennial Forage Grasses
}

\section{Philippe Barre $^{1, *}$, Lesley B. Turner ${ }^{2}$ and Abraham J. Escobar-Gutiérrez ${ }^{1}$}

1 INRA, UR4, Le Chêne RD 150, Lusignan 86600, France;

E-Mail: abraham.escobar@lusignan.inra.fr

2 IBERS, Aberystwyth University, Gogerddan Campus, Aberystwyth SY23 3EE, UK;

E-Mail: 1bt@aber.ac.uk

* Author to whom correspondence should be addressed; E-Mail: philippe.barre@lusignan.inra.fr; Tel.: +33-549-556-116; Fax: +33-549-556-044.

Academic Editor: Cory Matthew

Received: 12 May 2015 / Accepted: 17 August 2015 / Published: 25 August 2015

\begin{abstract}
Leaf length is a key factor in the economic value of different grass species and cultivars in forage production. It is also important for the survival of individual plants within a sward. The objective of this paper is to discuss the basis of within-species variation in leaf length. Selection for leaf length has been highly efficient, with moderate to high narrow sense heritability. Nevertheless, the genetic regulation of leaf length is complex because it involves many genes with small individual effects. This could explain the low stability of QTL found in different studies. Leaf length has a strong response to environmental conditions. However, when significant genotype $\times$ environment interactions have been identified, their effects have been smaller than the main effects. Recent modelling-based research suggests that many of the reported environmental effects on leaf length and genotype $\times$ environment interactions could be biased. Indeed, it has been shown that leaf length is an emergent property strongly affected by the architectural state of the plant during significant periods prior to leaf emergence. This approach could lead to improved understanding of the factors affecting leaf length, as well as better estimates of the main genetic effects.
\end{abstract}

Keywords: leaf length; forage; turf; grass; plant modelling 


\section{Introduction}

The leaf length of forage grasses shows high variability between species, ranging from a few centimeters to more than a meter. The choice of species for sowing in a sward depends on the use of the sward (e.g., grazing, silage or hay production, biomass production, and permanent versus short term grassland) and on environmental conditions (climate and soil). Once the choice of species has been made, there is still great within-species variation which can be optimized. In this paper we focus on the origin of this within-species variation in leaf length.

Leaf length is a key factor determining the vegetative yield of forage grasses, and has therefore become one of the main breeding objectives [1,2]. Many studies have been conducted to determine the morphological and physiological traits which could explain vegetative yield variation in swards. Leaf length, leaf elongation rate and yield per tiller (which are generally highly positively correlated) seem to be most important, ahead of tiller density which tends to become stabilized in dense canopies [3-7]. Apparently in contradiction with this, a study on perennial ryegrass [8] showed that the rate of tiller production, rather than leaf length, explained the difference in vegetative production after three cycles of divergent selection for dry matter yield. However, the yield data were obtained from spaced plants [9]. This confirms the hypothesis that the yields measured from spaced plants and dense canopies are not entirely explained by the same morphological characteristics, and that the yield per plant of spaced plants is not a good criterion for selection aiming to increase yield in swards [10]. The leaf length that maximizes vegetative yield depends on the cutting frequency [5,6,11]. Under infrequent cutting, long-leaved genotypes yield more than short-leaved genotypes. Conversely, under frequent cutting, short-leaved genotypes tend to yield more than long-leaved genotypes. Nevertheless, long-leaved genotypes show higher plasticity than short-leaved genotypes with regard to the cutting regime. Long-leaved genotypes can decrease their leaf length when cut frequently, whereas short-leaved genotypes cannot increase their leaf length when cut infrequently [12]. The consequence of this is that long-leaved genotypes seem better for vegetative yield in swards than short-leaved genotypes, irrespective of the cutting regime. However, cutting height is also important in this context. Indeed, there is genotype-dependent variation in the ability to adapt to severe defoliation by decreasing the height of the leaf growth zone, thus protecting caulinary meristems [13]. In contrast to dry matter yield, leaf length and related parameters evaluated on spaced plants, even on seedlings, can be good selection criteria for improving the vegetative yield of swards [14-17]. Moreover, leaf length is positively correlated with short-term intake when grazed by dairy cows $[18,19]$.

Leaf length in grasses plays an essential role in shaping the physical structure of the canopy and consequently on competition for light within the sward. One of the major adaptive responses to light competition in plants is an increase of plant height, i.e., leaf length during the vegetative period in grasses [20-24]. This increase in plant height is affected by phenotypic plasticity. Nevertheless, in a sward composed of different genotypes and/or species, phenotypic plasticity cannot always compensate for genetic differences between plants, ultimately leading to the death of some genotypes. For example, in a sward with long- and short-leaved genotypes of perennial ryegrass under infrequent cutting, the proportion of short-leaved genotypes decreases due to competition for light, as in Figure 1 [25]. Like other phototrophic organisms, light acquisition is essential for the survival of perennial forage grasses. In sown grasslands consisting of many genotypes and often of several 
species, the plant height of the different constituents should be optimized in order to avoid the fade-out of one of the species [26]. There are two possible strategies to optimize mixture composition. The first is to include constituents with similar patterns of seasonal growth which are therefore in competition for light acquisition. In this case, constituents with similar competitive ability, including plant height and tillering, must be chosen in order to avoid exclusion. The second strategy is to include constituents which grow at different periods of the year, i.e. asynchronous growth, which would provide more stable production over the growing season [27].

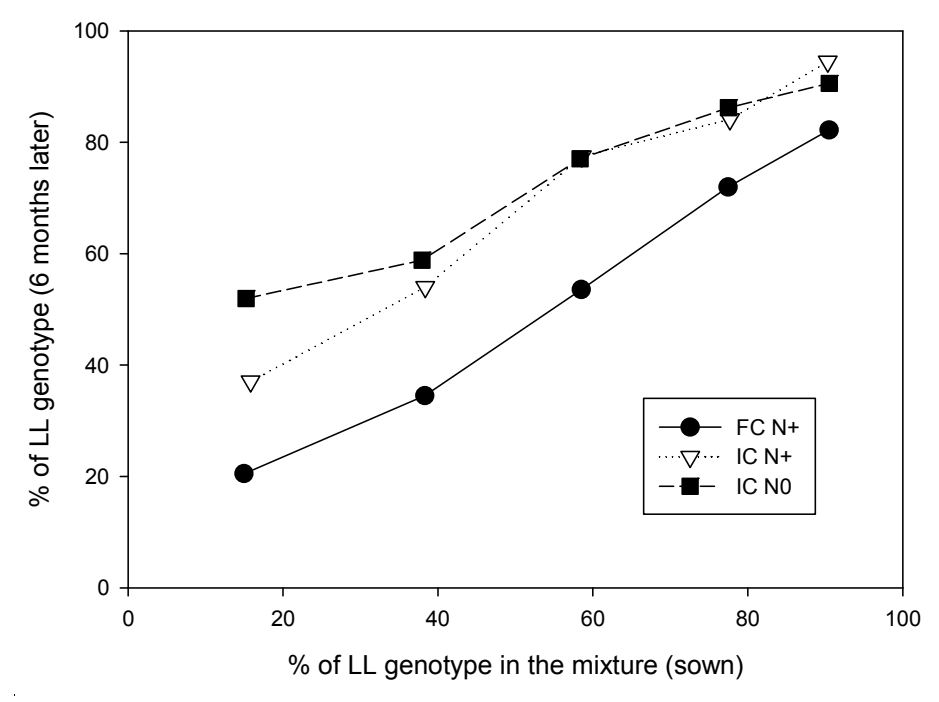

Figure 1. Genotypic responses of mixtures under three management regimes showing a decrease in the percentage of short-leaved genotypes under infrequent cutting and no change under frequent cutting. (FC N+, frequent cutting with nitrogen; IC N+, infrequent cutting with nitrogen; IC N0, infrequent cutting with no nitrogen). LL: long-leaved genotype. Figure from [25].

It is important to remember that leaf length in grasses is greatly influenced by the developmental stage of the plant: reproductive or vegetative [1]. Growth rate increases markedly following flower induction and before any visible stem elongation (Figure 2) [28-30]. This change in leaf growth rate seems to be due to an increase in cell division which could be related to environmental regulation of the gibberellins pathway [31-33]. Consequently, for a given genotype, leaf length varies greatly depending on whether the leaf grows on an axis which has been induced for flowering or not. Moreover, leaf elongation rate during the two growth phases seems to be genetically independent to a large extent [34]. This implies that a genotype $\times$ growth season (reproductive versus vegetative, i.e., spring versus fall) interaction is expected. In this paper we will focus on variation within a growing phase and the trait of interest will be leaf length (sheath and lamina) and not stem elongation.

The objective of this paper is to discuss the origin of variation in leaf length within perennial forage grasses, i.e., genetics (heritability and genetic architecture), environment (temperature, nitrogen, light) and genetic $\times$ environment interaction, and to produce new insights into this variation by including recent advances in plant morphogenesis modelling. 


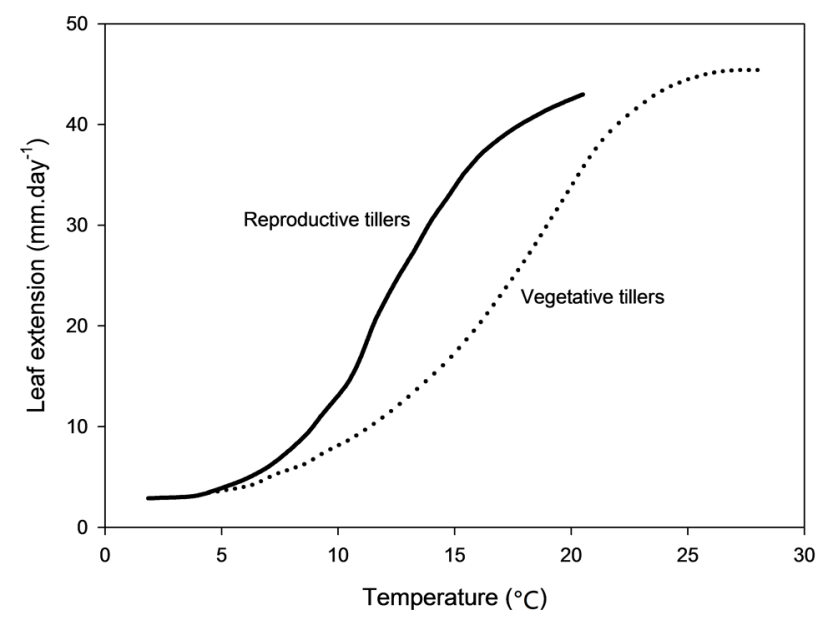

Figure 2. Contrasted responses of leaf extension to temperature before and after flowering induction in perennial ryegrass. Adapted from [30] with data from [35,36].

\section{Genetic Variation in Leaf Length}

\subsection{Heritability}

Broad-sense heritability $\left(\mathrm{H}^{2}\right)$ reflects all the genetic contributions to a population's phenotypic variance. It is calculated as the genetic variance divided by the sum of the genetic and the environmental variances: $H^{2}=\sigma_{G}^{2} /\left(\sigma_{G}^{2}+\sigma^{2}\right)$. By definition it depends on the genotypes included in the population and on the experimental design (field heterogeneity, one or several locations and years). Another estimate of broad-sense heritability, taking into account the number of replicates, is commonly used: $\mathrm{H}_{\text {average }}^{2}=\sigma_{\mathrm{G}}^{2} /\left(\sigma_{\mathrm{G}}^{2}+\sigma_{\mathrm{E}}^{2} \mathrm{n}\right)$ with $\mathrm{n}$ being the number of replicates. The $\mathrm{H}_{\text {average }}^{2}$ useful to assess the accuracy in the prediction of genotypic values, but since it depends on the experimental design it should not be used to compare studies. Generally comparison of heritabilities should be done with caution. In one location, during one growing phase, on spaced-plants and on equivalent leaves (same rank), leaf length broad-sense heritability $\left(\mathrm{H}^{2}\right)$ is high: above 0.65 [37-39]. It decreases when several environments and/or years are taken into account and also, as expected, when reproductive and vegetative growing stages are included: 0.3-0.6 [38,40-43]. Differences in vernalization requirements between genotypes exist in perennial grasses [44-46] and could lead to differences in the date of flower induction, which in turn could lead to differences in leaf length. These differences in leaf length between genotypes do not reflect true differences in leaf length potential but rather differences in earliness of flower induction. This phenomenon could lead to false genotype $\times$ environment interactions with regard to leaf length.

Narrow sense heritability $\left(\mathrm{h}^{2}\right)$ is defined as the additive variance divided by the phenotypic variance: $h^{2}=\sigma^{2} \mathrm{~A} / \sigma^{2} \mathrm{P}$, with the additive variance being the variance of the average effects of the alleles, representing the genetic component of variance responsible for parent-offspring resemblance. $\mathrm{h}^{2}$ is directly linked to the expected genetic gain. The deviation from this expectation is due to interaction between alleles of the same locus (dominance) or of different loci (epistasis). Narrow sense heritability of leaf length is high, above 0.65 , which reveals large additive effects and small dominance and epistatic effects $[17,47]$. 
Leaf length has been demonstrated to respond to selection. Several divergent selections for leaf length or leaf growth parameters evaluated on spaced plants showed strong responses with realized heritabilities from 0.2 to 0.6 depending on the plant material, as in Figure $3[15,48,49]$. Moreover, selection for leaf length on spaced plants had an effect on the vegetative yield in swards $[6,14,16]$.

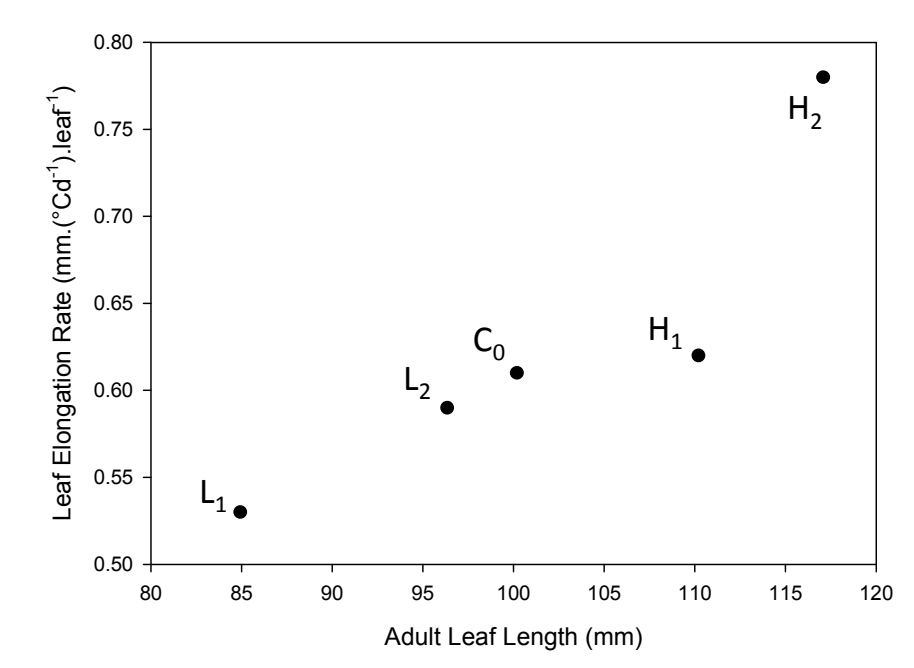

Figure 3. Response of leaf elongation rate and adult leaf length to divergent selection for lamina length on spaced plants (adapted from [15]). Means of long-leaved (H) and short-leaved (L) populations after 1 or 2 years of selection and mean of the initial $\left(\mathrm{C}_{0}\right)$ population. Examples of a turf and a forage variety are also presented.

In conclusion, considerable variation in leaf length exists within grass species, and, when measured properly (same leaf rank, same growing stage: reproductive or vegetative, no stem elongation), leaf length appears to be highly heritable and to respond to selection even when genotype $\times$ environment interactions are present.

\subsection{Genetic Architecture}

Several QTL studies on leaf length or related parameters (leaf elongation rate LER, plant height at vegetative stage) have been performed on forage grasses (mainly on perennial ryegrass) showing the complex genetic architecture of these traits Table 1 [50]. QTL with small effects, i.e., explaining less than $15 \%$ of the phenotypic variance, have been detected on all seven chromosomes. Moreover, the QTL together commonly explained less than half of the phenotypic variance. This seems to be the case even in crosses between forage and turf genotypes [51]. QTL often have inconsistencies between cuts within a year, between years and between locations.

These results could be seen to contradict the high heritability of this trait, but there are several possible explanations. It is not surprising to find different QTL for leaf length parameters in the reproductive stage in spring (even very early in floral development) and in the vegetative stage in autumn. Indeed, the limitations to leaf growth in the two stages are not the same [32]. Another source of variability arises from the way in which the measurements of leaf length are taken. Ideally, to be comparable between genotypes, the same leaf rank must be measured. Often this is not possible in the field and the youngest fully emerged leaf or plant/leaf height is measured. Regrowth after cutting to a 
particular plant height has also been used. The most appropriate measurement will depend on the circumstances of the experiment. Other than these physiological considerations, if leaf length genetic variation is based on many genes with small effects, it is impossible to detect them all with the population sizes historically used in QTL studies on forage grasses (from 100 to 400 genotypes). Randomly different QTL can be obtained in the same environment with two small (100-500) sets of plants from the same population; this is called the Beavis effect [52]. Different QTL could be detected in different environments if an environment has a high error variance that prevents the detection of a QTL [53]. In addition, QTL $\times$ environment interactions may well impact on the inconsistency of QTL.

Table 1. QTL for leaf length and related parameters in perennial ryegrass. The percentages of phenotypic variance are given for each linkage group (LG).

\begin{tabular}{|c|c|c|c|c|c|c|c|c|c|}
\hline Ref. & Parents & Traits & LG1 & LG2 & LG3 & LG4 & LG5 & LG6 & LG7 \\
\hline [39] & Pop8490 & Leaf length & & & & 13 & & & \\
\hline [41] & WSC F2 Perma $\times$ Aurora & & 12 & 11 & 9 & 10 & 25 & $31-38$ & 15 \\
\hline [54] & $\begin{array}{l}\text { ILGI p152/112 mapping } \\
\text { family }\end{array}$ & & & & & & 6 & & \\
\hline [42] & $\begin{array}{l}\text { North African } \times \text { Aurora F1 } \\
(\mathrm{NAx} \times \text { AU6) }\end{array}$ & Leaf area & & & 12 & & & 6 & \\
\hline [39] & Pop8490 (FL42 × FC61) & $\begin{array}{l}\text { Lamina length in } \\
\text { spring }\end{array}$ & & 9 & & 9 & & & 16 \\
\hline [39] & Pop8490 (FL42 × FC61) & $\begin{array}{l}\text { Lamina length in } \\
\text { autumn }\end{array}$ & & $8-18$ & & 10 & & 12 & 9 \\
\hline [40] & $\begin{array}{l}\text { Grasslands Impact } \times \\
\text { Grasslands Samson }\end{array}$ & $\begin{array}{l}\text { Lamina length in } \\
\text { autumn }\end{array}$ & 13 & 5 & $14-10$ & $14-14$ & & & 6 \\
\hline [43] & WSC F2 Perma $\times$ Aurora & $\begin{array}{l}\text { Leaf extension } \\
\text { rate (LER) }\end{array}$ & & 14 & 11 & & & & \\
\hline [40] & $\begin{array}{l}\text { Grasslands Impact } \times \\
\text { Grasslands Samson }\end{array}$ & LER in spring & & & & & & 13 & \\
\hline [39] & Pop8490 & LER in autumn & & & & 11 & & & \\
\hline [40] & $\begin{array}{l}\text { Grasslands Impact } \times \\
\text { Grasslands Samson }\end{array}$ & LER in autumn & 9 & & $26-27$ & & & & $5-8$ \\
\hline [55] & $\begin{array}{l}\text { Three connected } \\
\text { populations (elite material) }\end{array}$ & $\begin{array}{l}\text { Vegetative plant } \\
\text { height in spring }\end{array}$ & & $6-5$ & 5 & & $4-4$ & $4-4$ & $4-9$ \\
\hline [55] & $\begin{array}{l}\text { Three connected populations } \\
\text { (elite material) }\end{array}$ & $\begin{array}{l}\text { Vegetative plant } \\
\text { height in autumn }\end{array}$ & 3 & & & $7-6$ & 4 & & 4 \\
\hline [56] & WSC F2 Perma $\times$ Aurora & $\begin{array}{l}\text { Flag lamina } \\
\text { length * }\end{array}$ & & & & & & & 10 \\
\hline [56] & $\begin{array}{l}\text { ILGI p152/112 mapping } \\
\text { family }\end{array}$ & & & & & & & & 20 \\
\hline [57] & $\begin{array}{l}\text { Italian Veyo } \times \text { Danish } \\
\text { Falster }\end{array}$ & & & 11 & & $13-12$ & & 17 & \\
\hline
\end{tabular}

* Flag lamina lengths have been added even though not directly related to leaf length before stem elongation.

In conclusion, leaf length in forage grasses has a complex genetic architecture which seems to impede the detection of consistent QTL. The consequence for plant breeding is that, unless some 
strong QTL are identified (alleles leading to a dwarf or giant phenotype), it would be better to use molecular markers for predicting genetic values than for pyramiding favorable alleles. Phenotypic selection seems to have accumulated favorable alleles at different loci and often in a heterozygous state.

\section{Environmental and Genetic $\times$ Environmental Interaction Effects on Leaf Length}

Abundant empirical evidence demonstrates that leaf length exhibits a very high plasticity to environmental factors. Indeed, both theoreticians and experimentalists recognize that leaf length responds to sward management and to various environmental factors such as, but not limited to, temperature, nitrogen and water supply, defoliation frequency and intensity, light quantity and quality [29,58-61].

The length of a leaf is determined by its constituent cells and their length. The number of cells and the length of these cells result from cell division and elongation processes. Cell division plays a major role in the variation of leaf length within and between species [62,63]. It appears that these cellular processes are under the influence of the length of the enclosing sheaths both directly and indirectly. Experimental modifications to incise or artificially increase the pseudostem tube length directly affected the length of the leaf elongation zone and the final length of the cells [63,64]. Furthermore, modification of the pseudostem tube length with, for example, an opaque plastic tube, could also indirectly affect cell dynamics via control of the timing of leaf tip emergence [65]. Delaying or anticipating this event could modify both the placement of the sheath-blade boundary and the total cell number, as cessation of cell division at the base of the leaf could be triggered at the moment of leaf tip emergence from the previous sheath $[63,64]$. These effects may be light mediated. In order to determine (i) if physical factors other than light are involved in these responses, (ii) if this putative light effect is changed by qualitative or quantitative spectral modification, and (iii) if sheath elongation is also dynamically affected by pseudostem length, [66,67] tested the effect of pseudostem extension with plastic tubes on the leaf growth of uncut tall fescue plants. Tubes with contrasting optical properties were used: red-colored tubes which affect the "blue" domain of the spectrum, green-colored tubes which affect the Red: Far Red ratio, transparent tubes and opaque foil tubes. It appeared that reducing the passage of light through the tubes increased leaf elongation, and the length of leaves and sheaths. The effects of red and green tubes were not significantly different. These results support the hypothesis that light mediates the pseudostem morphogenetic effect. Furthermore, in this context, leaf elongation does not react to a qualitative modification of a unique domain in the light spectrum, but rather to a quantitative general decrease in irradiance [67]. Consequently, the pseudostem seems to play an essential morphogenetic role in the control of leaf elongation, mainly due to its impact on the length of the leaf growth zone and the timing of leaf tip emergence.

Genetic $\times$ environmental interactions on leaf length have been observed in multi-site trials and in trials in semi-controlled environments varying for environmental factors such as temperature, nitrogen and water supply, defoliation frequency and intensity, and light quantity and quality. Of course, the level of interaction depends on both the genetic and the environmental variation, but in general the effect of the interaction is smaller than the principal effects. For example, a study on the response of leaf length to light quality and quantity in several perennial ryegrass genotypes showed a significant 
genotype $\times$ environment interaction but with a smaller effect than the principal effects [20]. Furthermore, in perennial ryegrass, a divergent selection for LER in response to light (green filter versus transparent filter) did not create progeny with significantly different LER in response to light, as seen in Figure 4 [51].

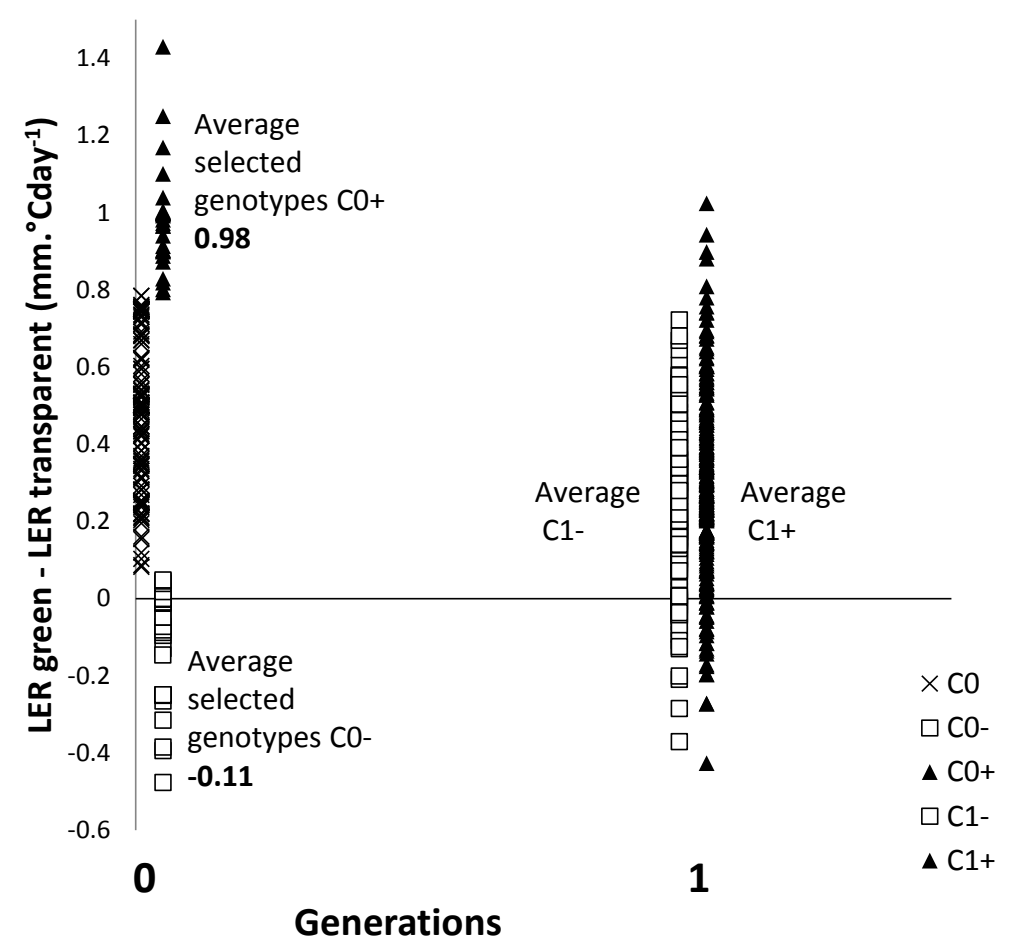

Figure 4. Divergent mass selection for LER in response to light (LER under green filter minus LER under transparent filter) in perennial ryegrass. Initial population: $\mathrm{C} 0$ and the next generation after intercrossing the selected genotypes: C1 (EU project GRASP).

\section{The Added Value of Plant Modelling}

Recent modelling-based research suggests that many of the reported environmental effects on leaf length and genotype $\times$ environment interactions could be biased; they have included both the effect of environment and the effect of self-regulatory processes during plant development [66]. Indeed, it has been shown that leaf length is an emergent property strongly affected by the architectural state of the plant during significant periods prior to leaf emergence.

As discussed above, leaf length is under genetic control, is highly heritable, and shows significant genetic variation. Nevertheless, this trait displays high plasticity that could be mediated by self-regulatory processes. Thus, leaf length is directly affected by the sheath length of the preceding leaf on the same tiller $[61,63,64]$ in a sort of recursive loop (Figure 5). These concepts were integrated into a cybernetic framework [66]. Briefly, leaf growth follows a Beta integral function [68]. The relationship between the length of the pseudostem i.e., series of sheaths from which a leaf emerge and the final length of the leaves, has been conceptualized and used to generate a growth potential (created by cell division and by the length of the leaf elongation zone) that is integrated while the leaf grows inside the pseudostem, before its tip emerges. The first phase of the growth, inside the pseudostem 
tube, is generic for all leaves. When the leaf tip emerges, the value of the growth potential is carried forward as the final length parameter of the growth function. This integration is taken as a synthesis-degradation process. Therefore, the longer the time elapsed from the beginning of leaf growth, the longer the final length. At this moment the proportion of sheath and of blade will also be determined according to a function described in [61]. It was found that the ratio between leaf length and sheath length of the preceding leaf is quasi-constant for a given genotype under a given environment. Model behavior and emergent properties were highly consistent with observations regarding plant morphological development, genetic variability and plasticity.

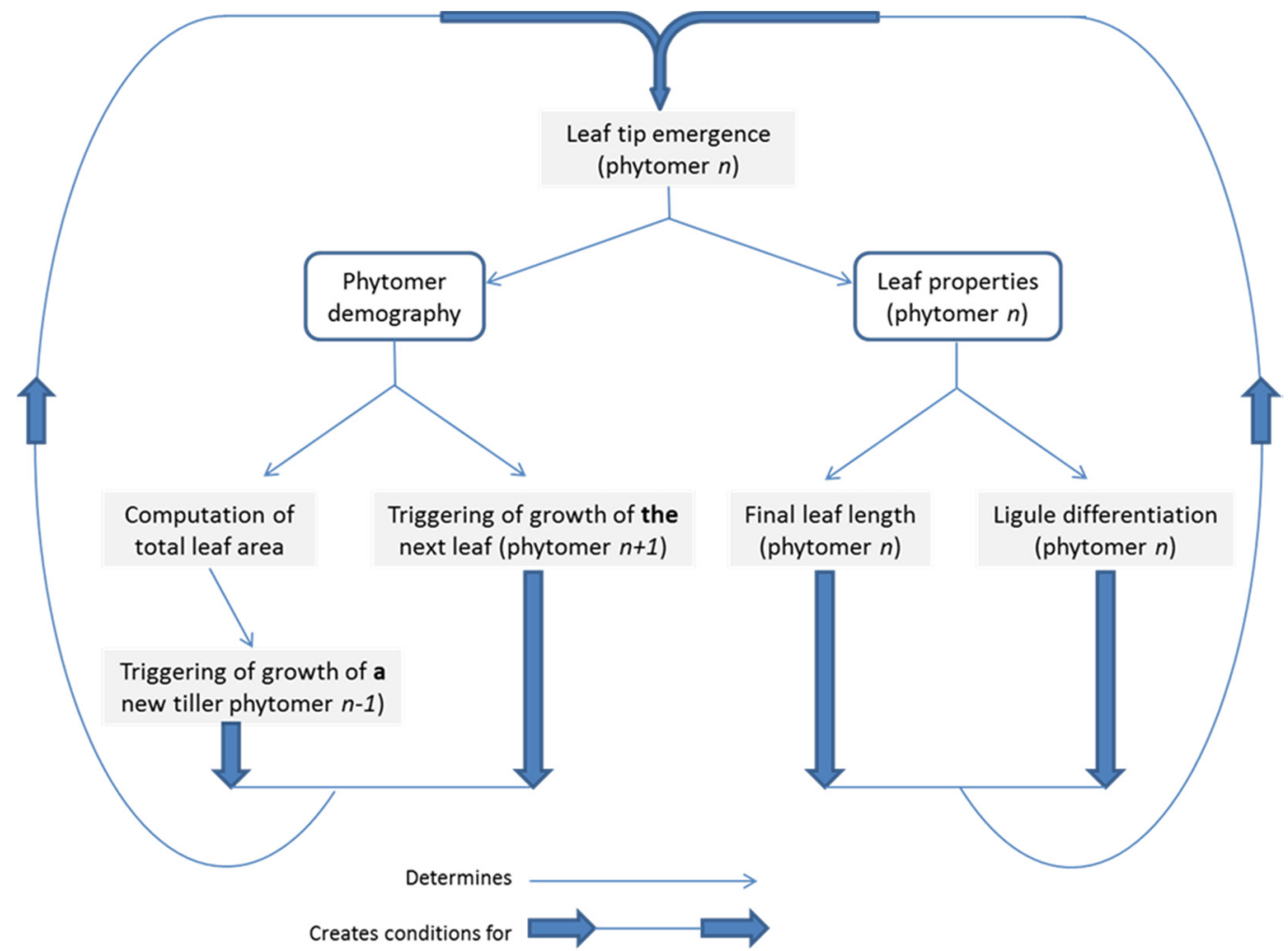

Figure 5. Diagram showing the cybernetic scheme implemented in the model. The recursive call to these rules automatically generates the morphology of the virtual plant by determining the number of leaves and their lengths.

A practical application of the model is that it is always possible to invert the process and to estimate the parameters of leaf growth from a range of measurements of leaf and sheath length for the preceding leaf of a given genotype in a given environment. All the measured plants have to be either vegetative or reproductive but not a mix of both. Thus, it is possible to compare genotypes and environments either by comparing the parameters of the model (not always explicit) or by comparing the simulated length of leaves of the same rank or of the same sheath length for the preceding leaf. Finally, it allows the architectural structure of the tiller and plant to be taken into account. Thus, genetic and environment effects can be properly separated from architectural effects (Figure 6). 


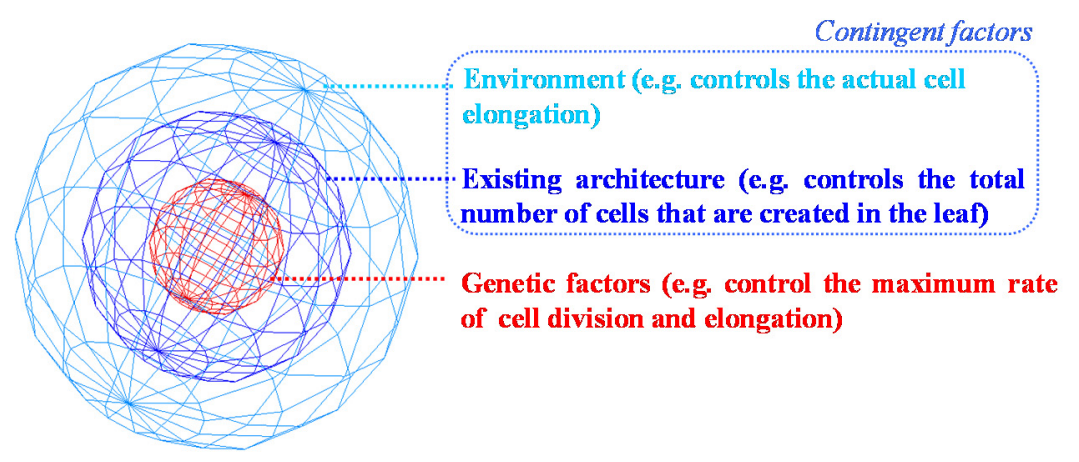

Figure 6. Putative nested levels of control determining ryegrass leaf length. Genetic factors regulate upstream processes that are modulated by lower contingent factors (adapted from [69]).

\section{Conclusions}

Leaf length of forage grasses is a key agronomic trait showing high intra-specific variation and plasticity in response to environmental factors. Part of the genotype $\times$ environment interaction could be explained by the methods used to measure leaf length. Since leaf length is strongly influenced by micro-environment, i.e., the status of the leaf in the plant including interactions with other organs, this micro-environment should be taken into account during the estimation of genetic values. Plant-morphogenesis models could help in extracting the genetic component of leaf length variation from variability due to uncontrolled micro-environments.

The identification of the respective biological scales, or levels in the regulatory network, at which genetic and/or environmental controls on leaf length are important is challenging.

Leaf length genetic architecture seems to involve many genes with small effects but with relatively high additive effects compared with dominance effects. This complex genetic architecture suggests larger populations should be used for QTL identification and for genomic selection. A better understanding of the sources of variation in leaf length should allow a better estimation of its genetic, components which should lead to the discovery of more consistent QTL.

\section{Acknowledgments}

The authors thank the European Union for founding the GRASP project, Thomas Lübberstedt for its coordination, and Isabelle Cameleyre, who participated actively in the experiment on LER in response to light quality and quantity.

The authors thank Laurent Hazard, Anthony Parsons, and Oxford University Press for Figures 1-3. Alban Verdenal kindly provided Figure 6.

\section{Author Contributions}

All authors contributed equally to the conception and writing of the paper. 


\section{Conflicts of Interest}

The authors declare no conflict of interest.

\section{References}

1. Wilkins, P.W. Breeding perennial ryegrass for agriculture. Euphytica 1991, 52, 201-204.

2. Humphreys, M.O. Genetic improvement of forage crops-Past, present and future. Can. J. Agr. Sci. 2005, 143, 441-448.

3. Zarrough, K.M.; Nelson, C.J.; Coutts, J.H. Relationship between tillering and forage yield of tall fescue. I. Yield. Crop Sci. 1983, 23, 333-337.

4. Horst, G.L.; Nelson, C.J.; Asay, K.H. Relationship of leaf elongation to forage yield of tall fescue genotypes. Crop Sci. 1978, 18, 715-719.

5. Rhodes, I. The relationship between productivity and some components of canopy structure in ryegrass (Lolium spp.). I. Leaf length. Can. J. Agr. Sci. 1969, 73, 315-319.

6. Hazard, L.; Ghesquière, M. Productivity under contrasting cutting regimes of perennial ryegrass selected for short and long leaves. Euphytica 1997, 95, 295-299.

7. Zarrough, K.M.; Nelson, C.J.; Coutts, J.H. Relationship between tillering and forage yield of tall fescue. II. Pattern of tillering. Crop Sci. 1983, 23, 338-342.

8. Ceccarelli, S.; Falcinelli, M.; Damiani, F. Selection for dry matter yield in Lolium perenne L. II. Correlated responses under two cutting regimes. Can. J. Plant. Sci. 1980, 60, 501-508.

9. Ceccarelli, S.; Falcinelli, M.; Damiani, F. Selection for dry matter yield in Lolium perenne L. I. Direct response to selection. Can. J. Plant. Sci. 1980, 60, 491-500.

10. Hayward, M.D.; Vivero, J.L. Selection for yield in Lolium perenne. II. Performance of spaced plant selections under competitive conditions. Euphytica 1984, 33, 787-800.

11. Hazard, L.; Ghesquière, M.; Betin, M. Breeding for management adaptation in perennial ryegrass (Lolium perenne L.). I. Assessment of yield under contrasting cutting frequencies and relationships with leaf morphogenesis components. Agronomie 1994, 14, 259-266.

12. Hazard, L. Plasticity gives a greater flexibility to forage grass use. Fourrages 1996, 147, 293-302.

13. Gastal, F.; Dawson, L.A.; Thornton, B. Responses of plant traits of four grasses from contrasting habitats to defoliation and n supply. Nutr. Cycling Agroecosyst. 2010, 88, 245-258.

14. Jones, R.J.; Nelson, C.J.; Sleper, D.A. Seedling selection for morphological characters associated with yield of tall fescue. Crop Sci. 1979, 19, 631-634.

15. Hazard, L.; Ghesquière, M.; Barraux, C. Genetic variability for leaf development in perennial ryegrass populations. Can. J. Plant. Sci. 1996, 76, 113-118.

16. Rhodes, I.; Mee, S. Changes in dry matter yield associated with selection for canopy characters in ryegrass. Grass Forage Sci. 1980, 35, 35-39.

17. Rhodes, I. The relationship between productivity and some components of canopy structure in ryegrass (Lolium spp.). III. Spaced plant characters, their heritabilities and relationship to sward yield. Can. J. Agr. Sci. 1973, 80, 171-176. 
18. Barrett, P.D.; Laidlaw, A.S.; Mayne, C.S.; Christie, H. Pattern of herbage intake rate and bite dimensions of rotationally grazed dairy cows as sward height declines. Grass Forage Sci. 2001, 56, 362-373.

19. Barre, P.; Emile, J.C.; Betin, M.; Surault, F.; Ghesquière, M.; Hazard, L. Morphological characteristics of perennial ryegrass leaves that influence short-term intake in dairy cows. Agron. J. 2006, 98, 978-985.

20. Barre, P.; Gueye, B.; Gastal, F. Effect of light quality and quantity on leaf growth in Lolium perenne L. In Sustainable Use of Genetic Diversity in Forage and Turf breeding, Proceedings of the EUCARPIA 2009, La Rochelle, France, 11-14 May 2009; Huyghe, C., Ed.; Springer: Berlin, Germany, 2010; pp. 61-65.

21. Kephart, K.D.; Buxton, D.R.; Taylor, S.E. Growth of C3 and C4 perennial grasses under reduced irradiance. Crop Sci. 1992, 32, 1033-1038.

22. Buxton, D.R.; Lentz, E.M. Performance of morphologically diverse orchardgrass clones in spaced and sward plantings. Grass Forage Sci. 1993, 48, 336-346.

23. Bahmani, I.; Hazard, L.; Varlet-Granchet, C.; Betin, M.; Lemaire, G.; Matthew, C.; Thom, E.R. Differences in tillering of long- and short-leaved perennial ryegrass genetic lines under full light and shade treatments. Crop Sci. 2000, 40, 1095-1102.

24. Gautier, H.; Varlet-Grancher, C. Regulation of leaf growth of grass by blue light. Physiol. Plant. 1996, 98, 424-430.

25. Hazard, L.; Ghesquière, M. Evidence from the use of isozyme markers of competition in swards between short-leaved and long-leaved perennial ryegrass. Grass Forage Sci. 1995, 50, 241-248.

26. Rhodes, I.; Stern, W.R. Competition for light. In Plant Relations in Pastures; CSIRO: East Melborne, Australia, 1978; pp. 175-189.

27. Prieto, I.; Violle, C.; Barre, P.; Durand, J.L.; Ghesquière, M.; Litrico, I. Complementary effects of species and genetic diversity on productivity and stability of sown grasslands. Nat. Plant. 2015, 1, 1-5.

28. Kemp, D.R.; Eagles, C.F.; Humphreys, M.O. Leaf growth and apex development of perennial ryegrass during winter and spring. Ann. Bot. 1989, 63, 349-355.

29. Gastal, F.; Belanger, G.; Lemaire, G. A model of the leaf extension rate of tall fescue in response to nitrogen and temperature. Ann. Bot. 1992, 70, 437-442.

30. Parsons, A.J.; Robson, M.J. Seasonal changes in the physiology of S24 perennial ryegrass (Lolium perenne L.). I. Response of leaf extension to temperature during the transition from vegetative to reproductive growth. Ann. Bot. 1980, 46, 435-444.

31. Ball, C.C.; Parsons, A.J.; Rasmussen, S.; Shaw, C.; Rowarth, J.S. Seasonal differences in the capacity of perennial ryegrass to respond to gibberellin explained. Proc. N. Z. Grassl. Assoc. 2012, 74, 183-188.

32. Parsons, A.J.; Rasmussen, S.; Liu, Q.; Xue, H.; Ball, C.; Shaw, C. Plant growth-Resource or strategy limited: Insights from responses to gibberellin. Grass Forage Sci. 2013, 68, 577-588.

33. Bernier, G. The control of floral evocation and morphogenesis. Ann. Rev. Plant Phys. Plant Mol. Biol. 1988, 39, 175-219.

34. Wilkins, P.W. Genotype harvesting frequency and genotype nitrogen level interactions for annual dry-matter yield in Lolium perenne in relation to breeding. Euphytica 1989, 41, 207-214. 
35. Peacock, M. Temperature and leaf growth in Lolium perenne. II the site of temperature perception. J. Appl. Ecol. 1975, 12, 115-123.

36. Peacock, J.M. Temperature and leaf growth in Lolium perenne. III. Factors affecting seasonal differences. J. Appl. Ecol. 1975, 12, 685-697.

37. Cooper, J.P.; Edwards, D. The genetic control of leaf development in Lolium. I. Assessment of genetic variation. Heredity 1961, 16, 63-82.

38. Auzanneau, J.; Huyghe, C.; Escobar-Gutierrez, A.J.; Julier, B.; Gastal, F.; Barre, P. Association study between the gibberellic acid insensitive gene and leaf length in a Lolium perenne L. synthetic variety. BMC Plant Biol. 2011, 11, 183-196.

39. Barre, P.; Moreau, L.; Mi, F.; Turner, L.; Gastal, F.; Julier, B.; Ghesquiere, M. Quantitative trait loci for leaf length in perennial ryegrass (Lolium perenne L.). Grass Forage Sci. 2009, 64, 310-321.

40. Sartie, A.M.; Matthew, C.; Easton, H.S.; Faville, M.J. Phenotypic and QTL analyses of herbage production-related traits in perennial ryegrass (Lolium perenne L.). Euphytica 2011, 182, 295-315.

41. Kobayashi, S.; Humphreys, M.O.; Tase, K.; Sanada, Y.; Yamada, T. Molecular marker dissection of ryegrass plant development and its response to growth environments and foliage cuts. Crop Sci. 2011, 51, 600-611.

42. Pearson, A.; Cogan, N.O.I.; Baillie, R.C.; Hand, M.L.; Bandaranayake, C.K.; Erb, S.; Wang, J.; Kearney, G.A.; Gendall, A.R.; Smith, K.F.; et al. Identification of QTLs for morphological traits influencing waterlogging tolerance in perennial ryegrass (Lolium perenne L.). Theor. Appl. Genet. 2011, 122, 609-622.

43. Turner, L.; Cairns, A.; Armstead, I.; Thomas, H.; Humphreys, M.W.; Humphreys, M.O. Does fructan have a functional role in physiological traits? Investigation by quantitative trait locus mapping. New Phytol. 2008, 179, 765-777.

44. Andersen, J.; Jensen, L.; Asp, T.; Lübberstedt, T. Vernalization response in perennial ryegrass (Lolium perenne L.) involves orthologues of diploid wheat (Triticum monococcum) Vrn1 and rice (Oryza sativa) HD1. Plant Mol. Biol. 2006, 60, 481-494.

45. Jokela, V.; Virkajarvi, P.; Tanskanen, J.; Seppanen, M.M. Vernalization, gibberellic acid and photoperiod are important signals of yield formation in timothy (Phleum pratense). Physiol. Plant. 2014, 152, 152-163.

46. Fjellheim, S.; Boden, S.; Trevaskis, B. The role of seasonal flowering responses in adaptation of grasses to temperate climates. Front. Plant Sci. 2014, 5, doi:10.3389/fpls.2014.00431.

47. Ghesquière, M.; Hazard, L.; Betin, M. Breeding for management adaptation in perennial ryegrass (Lolium perenne L.). II. Genetic variability and heritability of leaf morphogenesis components. Agronomie 1994, 14, 267-272.

48. Edwards, D.; Cooper, J.P. The genetic control of leaf development in Lolium. II. Response to selection. Heredity 1963, 18, 307-317.

49. Reeder, L.; Sleper, D.; Nelson, C. Response to selection for leaf area expansion rate of tall fescue. Crop Sci. 1984, 24, 97-100.

50. Shinozuka, H.; Cogan, N.O.I.; Spangenberg, G.C.; Forster, J.W. Quantitative trait locus (QTL) meta-analysis and comparative genomics for candidate gene prediction in perennial ryegrass (Lolium perenne L.). BMC Genet. 2012, 13, 101-113. 
51. Barre, P.; Cameleyre, I.; Huyghe, C.; Gastal, F., Lübberstedt, T. INRA, Lusignan, France. Unpublished work, 2007.

52. Xu, S.Z. Theoretical basis of the beavis effect. Genetics 2003, 165, 2259-2268.

53. Bernardo, R. Molecular markers and selection for complex traits in plants: Learning from the last 20 years. Crop Sci. 2008, 48, 1649-1664.

54. Yamada, T.; Jones, E.S.; Cogan, N.O.I.; Vecchies, A.C.; Nomura, T.; Hisano, H.; Shimamoto, Y.; Smith, K.F.; Hayward, M.D.; Forster, J.W. QTL analysis of morphological, developmental, and winter hardiness-associated traits in perennial ryegrass. Crop Sci. 2004, 44, 925-935.

55. Pauly, L.; Flajoulot, S.; Garon, J.; Julier, B.; Beguier, V.; Barre, P. Detection of favorable alleles for plant height and crown rust tolerance in three connected populations of perennial ryegrass (Lolium perenne L.). Theor. Appl. Genet. 2012, 124, 1139-1153.

56. Armstead, I.; Turner, L.; Marshall, A.; Humphreys, M.; King, I.; Thorogood, D. Identifying genetic components controlling fertility in the outcrossing grass species perennial ryegrass ( Lolium perenne L.) by quantitative trait loci analysis and comparative genetics. New Phytol. 2008, 178, 559-571.

57. Studer, B.; Jensen, L.B. Hentrup, S.; Brazauskas, G.; Kölliker, R.; Lübberstedt, T. Genetic characterisation of seed yield and fertility traits in perennial ryegrass (Lolium perenne L.). Theor. Appl. Genet. 2008, 117, 781-791.

58. Barillot, R.; Frak, E.; Combes, D.; Durand, J.-L.; Escobar-Gutierrez, A.J. What determines the complex kinetics of stomatal conductance under blueless par in Festuca arundinacea? Subsequent effects on leaf transpiration. J. Exp. Bot. 2010, 61, 2795-2806.

59. Forde, B.J. Effect of various environments on the anatomy and growth of perennial ryegrass and cocksfoot. N. Z. J. Bot. 1966, 4, 13.

60. Duru, M.; Ducrocq, H. Growth and senescence of the successive grass leaves on a tiller. Ontogenic development and effect of temperature. Ann. Bot. 2000, 85, 635-643.

61. Verdenal, A.; Combes, D.; Escobar-Gutierrez, A.J. A study of ryegrass architecture as a self-regulated system, using functional-structural plant modelling. Funct. Plant Biol. 2008, 35, 911-924.

62. Gastal, F.; Barre, P.; Carré, S. What are the cellular components underlying the genetic diversity of leaf growth in Lolium perenne L.? In Sustainable Use of Genetic Diversity in Forage and Turf Breeding, Proceedings of the EUCARPIA 2009, La Rochelle, France, 11-14 May 2009; Huyghe, C., Ed.; Springer: Berlin, Germany, 2010; pp. 95-100.

63. Sugiyama, S. Developmental basis of interspecific differences in leaf size and specific leaf area among C3 grass species. Funct. Ecol. 2005, 19, 916-924.

64. Casey, I.; Brereton, A.; Laidlaw, A.; McGilloway, D. Effects of sheath tube length on leaf development in perennial ryegrass (Lolium perenne L.). Ann. Appl. Biol. 1999, 134, 251-257.

65. Wilson, R.E.; Laidlaw, A.S. The role of the sheath tube in the development of expanding leaves in perennial ryegrass. Ann. Appl. Biol. 1985, 106, 385-391.

66. Andrieu, B.; Hillier, J.; Birch, C. Onset of sheath extension and duration of lamina extension are major determinants of the response of maize lamina length to plant density. Ann. Bot. 2006, 98, $1005-1016$. 
67. Verdenal, A.; Combes, D.; Escobar-Gutiérrez, A.J. Programmable and self-organised processes in plant morphogenesis: The architectural development of ryegrass. In Studies on Complexity: Morphogenetic Engineering; Doursa, R.S., Michel, O., Eds.; Springer: Berlin, Germany, 2012; pp. 501-517.

68. Verdenal, A. De la Simulation de la Morphogénèse de L'appareil Aérien du Ray-Grass Anglais (Lolium Perenne L.). Exploration d'un Schéma Cybernétique Inspiré du Concept D'auto-Organisation et Applications. Ph.D. Thesis, The Université de Poitiers, Poitiers, France, December 2009; p.190.

69. Migault, V.; Combes, D.; Barre, P.; Gueye, B.; Louarn, G.; Escobar-Gutiérrez, A.J. Improved modelling of ryegrass foliar growth. In Proceedings of the Plant Growth Modeling, Simulation, Visualization and Applications-PMA12, Shanghai, China, 31 October-3 November 2012; IEEE: Beijing, China, 2012; pp. 282-288.

(C) 2015 by the authors; licensee MDPI, Basel, Switzerland. This article is an open access article distributed under the terms and conditions of the Creative Commons Attribution license (http://creativecommons.org/licenses/by/4.0/). 